\title{
Oxide Based Ceramic Coating on Al-4Cu Alloy by Microarc Oxidation
}

\author{
S. Cengiz, M. Tarakci, Y. Gencer*, A.O. Devecili and Y. Azakli \\ Gebze Institute of Technology, Department of Materials Science and Engineering \\ 41400 Gebze, Kocaeli, Turkey
}

\begin{abstract}
In this study the $\mathrm{Al}-\mathrm{Cu}$ aluminum alloy with $4 \mathrm{wt} \% \mathrm{Cu}$ was prepared under controlled atmosphere and coated by microarc oxidation technique for the durations of 40, 80, and $120 \mathrm{~min}$. The phase composition, surface roughness and hardness of the coating were characterized by X-ray diffraction, scanning electron microscopy, profilometry. The outer region contains larger sized porosities while fine porosities were formed in the inner dense region of the coating. The longer coating duration resulted in dense inner region with finely distributed $\alpha-\mathrm{Al}_{2} \mathrm{O}_{3}$ precipitates. The presence of $\mathrm{Cu}$ in the outer region is not significant while the presence of $\mathrm{Si}$ in inner region was lower than in the outer region. Mullite and $\gamma-\mathrm{Al}_{2} \mathrm{O}_{3}$ phases were formed for $40 \mathrm{~min}$ and $\alpha-\mathrm{Al}_{2} \mathrm{O}_{3}$ phase was additionally formed for $80 \mathrm{~min}$ and $120 \mathrm{~min}$ coating time. The coating thickness increased from $38 \mu \mathrm{m}$ (40 min) to $115 \mu \mathrm{m}(120 \mathrm{~min})$ while the surface roughness $\left(R_{\mathrm{a}}\right)$ increased from $5 \mu \mathrm{m}(40 \mathrm{~min})$ to $9 \mu \mathrm{m}(120 \mathrm{~min})$.
\end{abstract}

DOI: 10.12693/APhysPolA.123.445

PACS: 81.15.-z, 81.05.Bx

\section{Introduction}

Aluminum and its alloys are extensively used as engineering materials because of their important properties of high strength/density rate and recyclability $[1,2]$. Copper has been the most common alloying element for aluminum alloys. Copper-containing Al alloys are one of the promising materials for many industrial application such as aerospace and automotive [3, 4]. However, their weak tribological properties and low corrosion resistance in some environment reduce their usage. Many of surface modification methods either changes or affects adversely the bulk properties of the materials, as they need high temperature. Therefore the methods applied at high temperature are not suitable for the materials like aluminum and its alloys.

The anodic oxidation is extensively used surface modification technique for aluminum and its alloys. But, as the obtained coating thickness (maximally $50 \mu \mathrm{m}$ ) and hardness (maximally $800 \mathrm{HV}$ ) is very low and the process is not eco-friendly due to the acidic solutions used, which limits the usage of the process $[5,6]$. Furthermore, the fatigue strength decreases significantly after anodization due to the dissolution of the $\mathrm{Cu}$-rich intermetallics during the anodizing process of $\mathrm{Cu}$ containing $\mathrm{Al}$ alloys [7]. Microarc oxidation (MAO) coating is a promising technique to $\mathrm{Al}$ and its alloys due to its application at room temperature in eco-friendly solutions and resultant properties of coating such as high corrosion resistance, wear resistance, hardness, thickness and well adherence to the substrate [5, 8-10].

Most of the widely used $2 \mathrm{xxx}$ series of Al alloys contains approximately $4 \mathrm{wt} \% \mathrm{Cu}$. Therefore, in this study

*corresponding author; e-mail: gencer@gyte.edu.tr the surface of the $\mathrm{Al}-4$ wt\% $\mathrm{Cu}(\mathrm{Al}-4 \mathrm{Cu})$ alloy was coated by MAO technique for the durations of 40,80 and $120 \mathrm{~min}$. The coatings were characterized by X-ray diffraction (XRD), scanning electron microscopy-energy dispersive spectroscopy (SEM-EDS), profilometry.

\section{Experimental}

$\mathrm{Al}-\mathrm{Cu}$ alloy ingots were prepared by melting of commercially pure $\mathrm{Al}(99.8 \%)$ and $\mathrm{Cu}(99.99 \%)$ pieces and solidification in water cooled copper mold under controlled atmosphere. The samples with the dimensions of $50 \mathrm{~mm} \times 25 \mathrm{~mm} \times 4 \mathrm{~mm}$ were sliced from the ingot. The plate shaped substrates were ground using 1200 grit $\mathrm{SiC}$ paper, polished using $3 \mu \mathrm{m}$ alumina and ultrasonically cleaned in ethanol for $5 \mathrm{~min}$. The profilometry (Veeco Dektak 8) was utilized to analyze the surface topography of the substrates prior to MAO process. The MAO coating process was carried out by means of an asymmetric AC power supply. An electrolyte for MAO coating was prepared by dissolving of $12 \mathrm{~g} / 1 \mathrm{Na}_{2} \mathrm{SiO}_{3}$ and $2.5 \mathrm{~g} / 1$ $\mathrm{KOH}$ in distilled water. The samples were coated for the durations of 40,80 , and 120 min by keeping the bath temperature at $20^{\circ} \mathrm{C}$ using the same electrical parameters. The coated samples were rinsed in distilled water and then cleaned using ethanol. The surface roughness of the MAO coated samples was determined by means of the same profilometer using the same parameters used for bare substrates. Rigaku D-MAX 2200 X-ray diffractometer $(40 \mathrm{~kW}, 40 \mathrm{~mA})$, with a $\mathrm{Cu} K_{\alpha}$ radiation over a $2 \theta=20^{\circ}$ to $90^{\circ}$, was employed for the characterization of MAO coated $\mathrm{Al}-4 \mathrm{Cu}$ alloy substrates.

Further XRD scans of the 120 min MAO coating of $\mathrm{Al}-4 \mathrm{Cu}$ were carried out after removing approximately half of the coating thickness by conventional grinding. The surfaces of gold coated samples were examined by XL30 FEG ESEM. Then the samples were cut, mounted 
into epoxy resin, ground and polished to expose the cross-section of the coatings. The microstructural examination and determination of the chemical composition of the MAO coated Al-Cu alloy were performed by cross-sectional SEM-EDS analysis. The samples exposing the cross-section of the coating were gold coated before the SEM analysis.

\section{Results and discussion}

\section{1. $X R D$}

The XRD patterns obtained from the surface of MAO coated $\mathrm{Al}-4 \mathrm{Cu}$ alloy for the durations of 40,80 , and 120 min are shown in Fig. 1. The figure also shows the pattern obtained from the surface scan of $120 \mathrm{~min}$. MAO coated $\mathrm{Al}-4 \mathrm{Cu}$ after removing approximately half of the coating thickness by conventional grinding. The peaks belong to mullite $\left(3 \mathrm{Al}_{2} \mathrm{O}_{3} \cdot 2 \mathrm{SiO}_{2}\right)$ and $\gamma-\mathrm{Al}_{2} \mathrm{O}_{3}$ phases are seen for all coating durations and for ground sample. The presence of the mullite phase was attributed to the complex chemical reactions between electrolyte constituents and substrate during microarc formation $[1,5,10,11]$. $\alpha-\mathrm{Al}_{2} \mathrm{O}_{3}$ was not formed in the duration of $40 \mathrm{~min}$ but it started to form in the coating duration of $80 \mathrm{~min}$. The existence of $\alpha-\mathrm{Al}_{2} \mathrm{O}_{3}$ phase with higher intensity was detected at $120 \mathrm{~min}$ coating time. The increase in the intensity of $\alpha-\mathrm{Al}_{2} \mathrm{O}_{3}$ is further clearly confirmed from the ground surface of 120 min coated sample's XRD pattern. The increase in the intensity of $\alpha-\mathrm{Al}_{2} \mathrm{O}_{3}$ phase by coating time can be attributed to the increase in the coating thickness. The aluminum peaks originated from the substrate are also seen on the pattern of 40 min coated sample and ground sample.

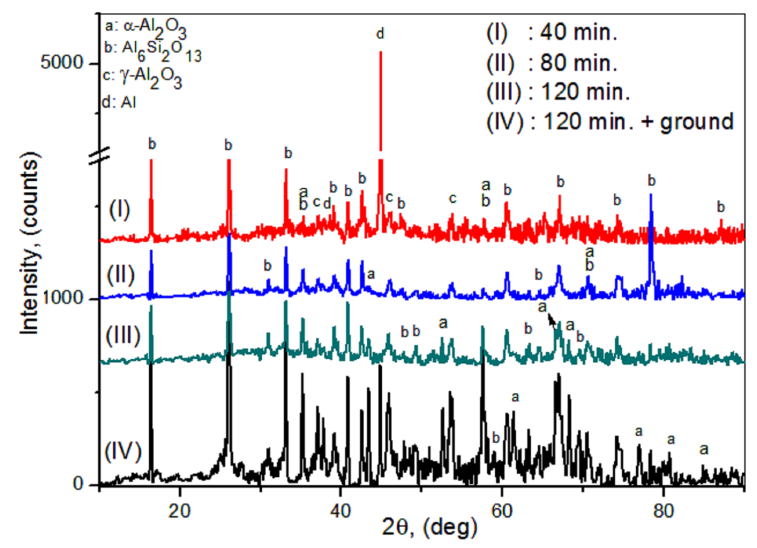

Fig. 1. XRD pattern from the surface of MAO coated $\mathrm{Al}-4 \mathrm{Cu}$ for 40,80 and $120 \mathrm{~min}$ and from the ground surface of 120 min coated $\mathrm{Al}-4 \mathrm{Cu}$.

\subsection{SEM analysis}

Figure 2 shows the SEM micrographs of coating surfaces of MAO coated $\mathrm{Al}-4 \mathrm{Cu}$ alloy. The small porosities are distributed randomly for the duration of $40 \mathrm{~min}$
(Fig. 2a). However, the number of small porosities decreases relatively and the number of bigger sized porosities increases and the microcracks are evident for the sample coated for 80 min (Fig. 2b). As shown in the SEM micrograph (Fig. 2c) of 120 min coated sample, the size of microcracks increases significantly and the surface of this sample is rougher than the samples coated for 40 and $80 \mathrm{~min}$. The surface of the samples coated for $40 \mathrm{~min}$ and 80 min was covered by melted and solidified features and contained sphere like solid features. The surface of the sample coated for 120 min has coarse surface with spongiform spheroid features. Furthermore, the typical MAO surface is seen on the surface of the coatings with semi-sphere like features the center of which was filled with porous material for $120 \mathrm{~min}$ coating. These spheroids which burst by the rapid cooling effect of cold electrolyte, contained some small porous features on their bottom center which resulted in material that transferred to the surface through microarc channels. A part of the molten metal and oxide mixture coming out of microarc channels spread and partly splashed on the surface of coating and then solidified by rapid cooling in the electrolyte. In the first $40 \mathrm{~min}$ of the coating time, the melted and rapidly solidified mullite phase was seen as covering the surface and the formation of this phase developed independently of cooling rate. Similar case was valid for the formation of $\gamma-\mathrm{Al}_{2} \mathrm{O}_{3}$ phase. The formation of cracks on the surface of MAO coated samples is attributed to low thermal shock resistance of oxide based ceramic coating by rapid cooling and high pressure created by sequential material transfer through microarc channels. The crack formation was less evident because of the high amount of sponge like features created on the coating with longer MAO time.

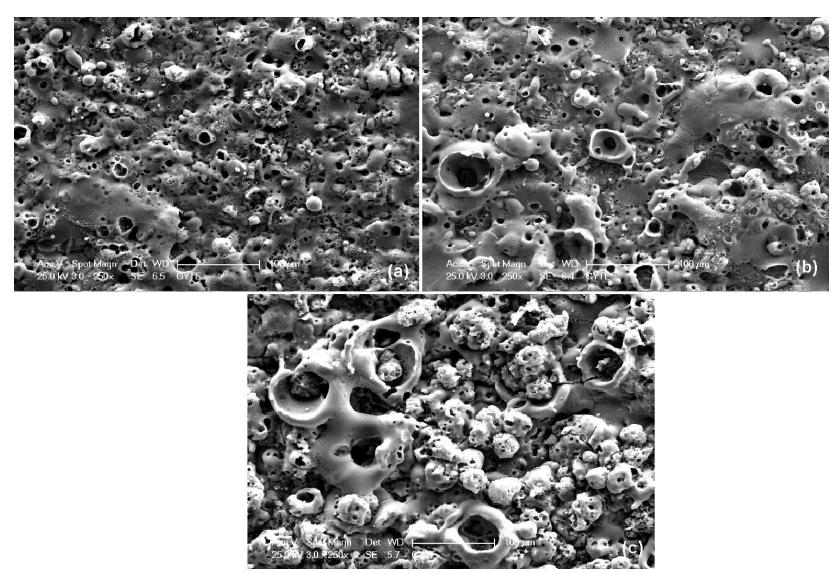

Fig. 2. SEM micrographs of coating surfaces of MAO coated $\mathrm{Al}-4 \mathrm{Cu}$ alloy: (a) $40 \mathrm{~min}$, (b) $80 \mathrm{~min}$, (c) $120 \mathrm{~min}$.

Figure 3 shows the cross-sectional SEM micrographs of the samples coated for 40, 80, and $120 \mathrm{~min}$. The figures show that the coatings adhered to the substrate perfectly and the interface is wavy in nature for 40 and 
80 min (Fig. 3a,b). The microcracks were seen in the cross-sectional views of the MAO coated samples for all coating durations. The detailed examination of the cross-sectional views showed that there were porosities with various sizes for all coating times. As the coating time increases, the size and amount of the porosities increases. While the bigger sized porosities were present in the other region (region I) of coating, the fine porosities were formed in the inner region (region II) of the coating. The thicknesses of both regions increase when the coating duration increases. However, the coating obtained for 120 min has relatively dense inner region with finely distributed precipitates (Fig. 3b).

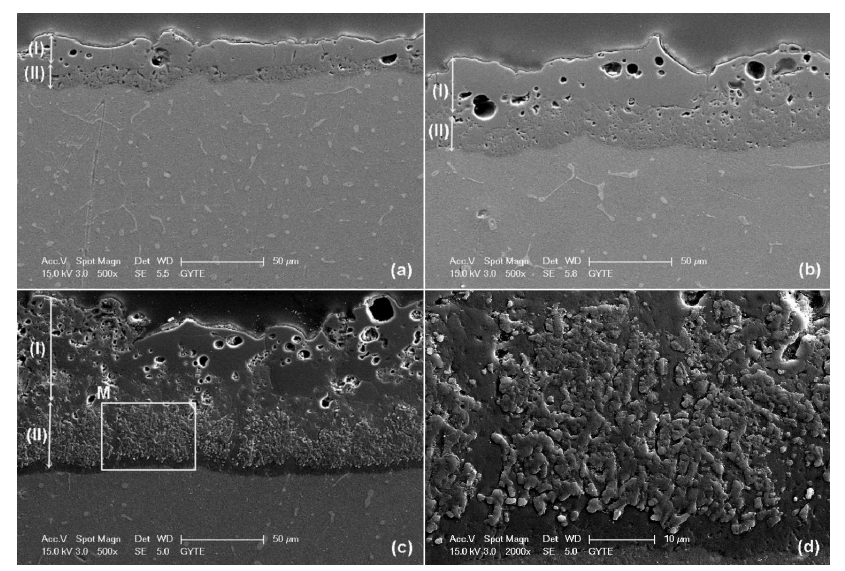

Fig. 3. Cross-sectional SEM micrographs of the samples coated (a) $40 \mathrm{~min}$, (b) $80 \mathrm{~min}$, (c) $120 \mathrm{~min}$, and (d) magnification of region " $\mathrm{M}$ " in (c).

The irregular shaped precipitates are more clearly seen in the magnified SEM micrograph of the dense region marked as "M" in Fig. 3c (Fig. 3d). These precipitates have much higher wear resistance than the surrounding matrix. As the XRD spectrum of the 120 min coated sample showed that the intensity of the $\alpha-\mathrm{Al}_{2} \mathrm{O}_{3}$ significantly increased when the approximately half of the coating ground was removed, it can be easily concluded that these precipitates are $\alpha-\mathrm{Al}_{2} \mathrm{O}_{3}$ phase. Similar findings were reported for some other MAO coated Al based alloys $[1,11] . \alpha-\mathrm{Al}_{2} \mathrm{O}_{3}$ phase precipitates in the dense region of the $\mathrm{MAO}$ coating is more stable than $\gamma-\mathrm{Al}_{2} \mathrm{O}_{3}$, as metastable $\gamma-\mathrm{Al}_{2} \mathrm{O}_{3}$ phase can transform to $\alpha-\mathrm{Al}_{2} \mathrm{O}_{3}$ at temperatures higher than $1000^{\circ} \mathrm{C}[12]$. The thicker MAO coating result in $\gamma-\mathrm{Al}_{2} \mathrm{O}_{3}$ phase in the inner regions transform to $\alpha-\mathrm{Al}_{2} \mathrm{O}_{3}$ due to the low thermal conduction of oxide based ceramic coating [8, 13].

The typical regional SEM-EDS spectrum obtained from regions I and II for the coating time of $120 \mathrm{~min}$ is illustrated in Fig. 4. The spectrum shows that $\mathrm{Al}$, $\mathrm{O}, \mathrm{Si}$ and $\mathrm{Cu}$ are present in both regions. However, the presence of $\mathrm{Cu}$ in the region $\mathrm{I}$ is not significant while the presence of $\mathrm{Si}$ in region II is higher than in region $\mathrm{I}$. The presence of $\mathrm{Si}$ was attributed to the sodium silicate in the electrolyte and its infiltration through microarc channels.
As $\mathrm{Cu}$ concentration is higher in region II than region I, the difference might be attributed to the sequential formation and dissolution of $\mathrm{Cu}-\mathrm{O}$ since $\mathrm{Cu}-\mathrm{O}$ is not very stable.

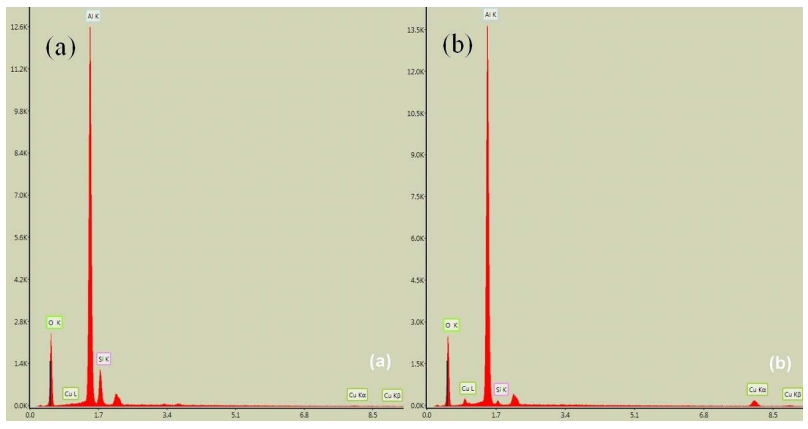

Fig. 4. The regional SEM-EDS spectrum obtained from 120 min coating of $\mathrm{Al}-4 \mathrm{Cu}$ : (a) regions $\mathrm{I}$ and (b) regions II (Fig. 3c).

\subsection{Coating thickness and surface roughness}

Figure 5 shows the change in coating thickness and surface roughness with MAO process time. As it is seen in Fig. 5 the coating thickness increases approximately linearly with the MAO coating time. The coating thickness is $38 \mu \mathrm{m}$ for the coating time of $40 \mathrm{~min}$ and it increases to $115 \mu \mathrm{m}$ for the coating time of $120 \mathrm{~min}$.

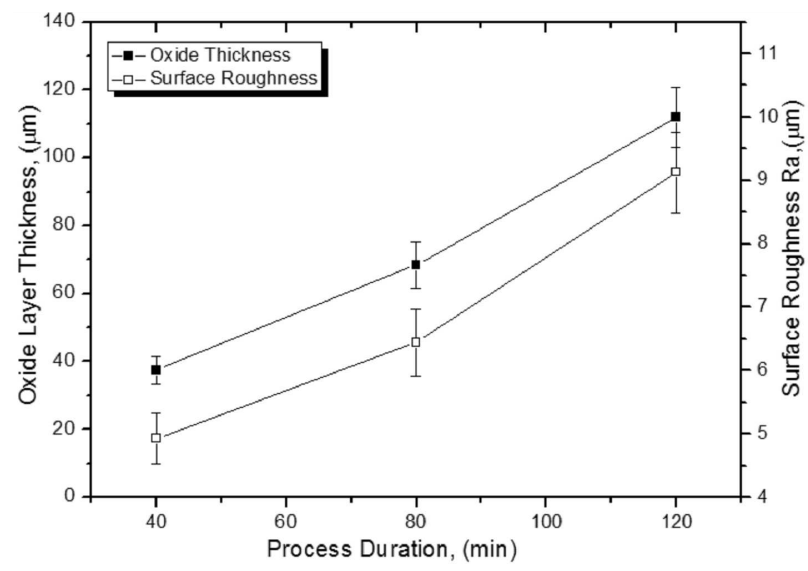

Fig. 5. The change in coating thickness and surface roughness with MAO process time for $\mathrm{Al}-4 \mathrm{Cu}$ alloy.

The surface roughness of the $\mathrm{Al}-4 \mathrm{Cu}$ alloy substrates were measured as approximately $0.30 \mu \mathrm{m}$ before MAO coating. The surface roughnesses of the samples were also increased approximately linearly with MAO process time. The surface roughness was measured as $5 \mu \mathrm{m}$ and $9 \mu \mathrm{m}$ for coating time of $40 \mathrm{~min}$ and $80 \mathrm{~min}$, respectively. The thickness increase is a natural result of the oxide material accumulation on the surface during MAO process. Increase in the thickness with MAO time resulted in increase in breakdown voltage and it intensified 
microsparks and consequently the surface roughness increased by coating time [14].

\section{Conclusions}

The coating by MAO adhered very well to the substrate. The coating is characterized as two main regions. While the bigger sized porosities were present in the outer region (region I) of coating, the fine porosities were formed in the inner region (region II) of the coating. The thicknesses of both regions increase when the coating duration increases. However, the coating obtained for $120 \mathrm{~min}$ has relatively dense inner region with finely distributed $\alpha-\mathrm{Al}_{2} \mathrm{O}_{3}$ precipitates. $\mathrm{Al}, \mathrm{O}, \mathrm{Si}$ and $\mathrm{Cu}$ are present in both regions. The presence of $\mathrm{Cu}$ in the region $\mathrm{I}$ is not significant while the presence of $\mathrm{Si}$ in region II is higher than in region $\mathrm{I}$. The coating contains the mullite and $\gamma-\mathrm{Al}_{2} \mathrm{O}_{3}$ phases for 40 min coating and $\alpha-\mathrm{Al}_{2} \mathrm{O}_{3}$ phase was also obtained for $80 \mathrm{~min}$ and 120 min coating time. The coating thickness increased linearly with coating duration from $38 \mu \mathrm{m}$ (40 min) to $115 \mu \mathrm{m}(120 \mathrm{~min})$. MAO coating process duration increased the surface roughness $\left(R_{\mathrm{a}}\right)$ from $5 \mu \mathrm{m}(40 \mathrm{~min})$ to $9 \mu \mathrm{m}$ (120 $\mathrm{min})$.

\section{References}

[1] M. Tarakci, Mater. Character. 62, 1214 (2011)
[2] F.T. Xu, Y. Xia, G. Li, Appl. Surf. Sci. 255, 9531 (2009)

[3] W.B. Xue, C. Wang, Y.L. Li, Z.W. Deng, R.Y. Chen, T.H. Zhang, Mater. Lett. 56, 737 (2002).

[4] L.A. Tarshis, Metall. Trans. 2, 2589 (1971)

[5] L.R. Krishna, A.S. Purnima, N.P. Wasekar, G. Sundararajan, Metall. Mater. Trans. A 38A, 370 (2007)

[6] H.Y. Hsiao, H.C. Tsung, W.T. Tsai, Surf. Coat. Technol. 199, 127 (2005).

[7] R.G. Rateick, R.J. Griffith, D.A. Hall, K.A. Thompson, Mater. Sci. Tech.-Lond. 21, 1227 (2005)

[8] X. Nie, E.I. Meletis, J.C. Jiang, A. Leyland, A.L. Yerokhin, A. Matthews, Surf. Coat. Technol. 149, 245 (2002)

[9] E. Matykina, R. Arrabal, A. Mohamed, P. Skeldon, G.E. Thompson, Corros. Sci. 51, 2897 (2009)

[10] A.L. Yerokhin, X. Nie, A. Leyland, A. Matthews, S.J. Dowey, Surf. Coat. Technol. 122, 73 (1999).

[11] Y. Gencer, A.E. Gulec, J. Alloy Comp. 525, 159 (2012)

[12] S.G. Xin, L.X. Song, R.G. Zhao, X.F. Hu, Surf. Coat. Technol. 199, 184 (2005)

[13] L. Yerokhin, L.O. Snizhko, N.L. Gurevina, A. Leyland, A. Pilkington, A. Matthews, J. Phys. D Appl. Phys. 36, 2110 (2003)

[14] W.B. Xue, Z.W. Deng, R.Y. Chen, T.H. Zhang, Thin Solid Films 372, 114 (2000) 